\title{
Do Exchange Rate Series Present General Dependence? Some Results using Recurrence Quantification Analysis
}

\author{
Teresa Aparicio, ${ }^{*}$ Eduardo F. Pozo, Dulce Saura \\ University of Zaragoza, Spain \\ *epozo@unizar.es
}

\begin{abstract}
In this paper, we apply a methodology based on the "Recurrence Quantification Analysis" to four daily exchange rate returns series. Our aim is to discover if they exhibit some kind of underlying structure, and to find an economic explanation for the behavior of exchange rates. Our results show the existence of structure in all series that, in certain cases, can be identified as non-linear deterministic. We also conclude that, in general, the underlying structure tends to disappear in the most recent periods.
\end{abstract}

Keywords: Exchange Rates, General dependence, Nonlinear Dynamics, Recurrence Plot, Recurrence Quantification Analysis

\section{Introduction}

In the last 30 years, economists have made a great effort to try to explain (and to predict) the evolution of exchange rate behavior. After the establishment of the floating exchange rate system, the first objective was to try to find a theoretical explanation for the large exchange rate fluctuations that, from then on, began to occur: rational expectations models, portfolio models, monetary models, etc., were formulated. The empirical failure of these models ${ }^{1}$ led economists to try other approaches (see, for example, De Grauve and Grimaldi, 2006), the micro-foundations underlying international relations (Obstfeld and Rogoff, 1995), the analysis of the "micro-structure" of foreign exchange markets (Evans and Lyons, 2002), the nonlinearities caused by the existence of heterogeneous agents (De Grauve and Grimaldi, 2005 and Bask, 2007), etc. From the empirical point of view, there is also abundant literature focused on the study of exchange rate series. Many of these papers analyze whether irregular fluctuations are the result of nonlinear relations. The general objective of much of this work is to improve the interpretation of these oscillations, and to develop estimation and forecasting techniques. For example, Hsie (1989), West and Cho (1995), Brooks and Hinich (1998), and Neely (1999) apply ARCH-GARCH structures. Others, e.g. Mizrach (1996), Serletis and Shahmoradi (2004), and Das and Das (2007) focus on the methodology of non-linear chaotic dynamics. Franses and Van Homelen (1998), and Nag and Mitra (2002) use neural networks. Other papers combine different approaches: for example, Lisi and Schiavo (1999), Mitra and Mitra (2006), and Hinich and Serletis (2007).

Much of the literature concludes that exchange rate series exhibit a non-linear structure. However, there are significant discrepancies concerning the stochastic or deterministic nature of this non-linearity. In our view, these discrepancies are due, not only to the variety of analytical techniques employed, but also to the characteristics of the series considered in each case: sample size, the period analyzed, the periodicity of the data (intraday, daily, monthly,), etc. The objective of this paper is twofold:

- To confirm if the series of exchange rates object of our study present some kind of structure, and to try to provide evidence of their stochastic or deterministic nature.

- To analyze whether there are significant changes in the underlying dynamics throughout the period considered.

To fulfill these objectives, we will use the methodology developed in Aparicio et al. (2008 and 2011), based on the so-called "Recurrence Quantification Analysis" proposed by Zbilut and Webber (1992) and Webber and Zbilut (1994). This procedure presents clear advantages over other analytical methods, among which we highlight simplicity of implementation and interpretation, and fewer prior data base requirements. Other authors emphasize the advantages of this technique. For example, Casdagli (1997)

${ }^{1}$ Obstfeld and Rogoff (2000) state that the exceedingly weak relationship between exchange rates and virtually any macro-economic aggregates constitutes one of the six major puzzles in international macro-economics. 
affirms that techniques based on recurrence plots provide a unified framework for addressing the principal objectives of nonstationary time series analysis: characterization, prediction, change point detection and hypothesis testing. The structure of the paper is as follows: in Section 2, we present an overview of the methodology used. In Section 3, we apply these test procedures to the selected exchange rate series. Finally, Section 6 provides a summary of our main conclusions.

\section{Test procedure: Recurrence Plots and Recurrence Quantification Analysis}

In this section, we outline the methodology used in this paper, which is described in detail in Aparicio et al. (2008). The starting point is a graphic tool called Recurrence Plot (RP), proposed by Eckmann et al. (1987) to detect patterns of recurrence in the data, one of the most important characteristics of dynamic systems. Briefly, an RP is a two-dimensional representation of the data series obtained by plotting a point on the $i-j$ plane if observation $x(i)$ is close to observation $x(j)$. Therefore, it is necessary to define a threshold or distance " $r$ " that determines the criterion of closeness. ${ }^{2}$ However, since an RP is a tool of a visual and qualitative nature, its interpretation is sometimes complicated and its results are not always conclusive. To overcome this problem, Zbilut and Webber (1992) and Webber and Zbilut (1994) design a procedure, which they call "Recurrence Quantification Analysis" (RQA), to quantify the information supplied by the RP. It is based on certain simple pattern recognition algorithms that enable the summary of information from the RP in a set of indicators or statistics. RPs and RQA have been used to analyze time series in Physics, Chemistry, Biology and, more recently, in Economics. For example, Holyst et al. (2001), Belaire et al. (2002), Strozzi et al. (2002 and 2007), and Hirata and Aihara (2012) apply this technique to series of exchange rates; Fabretti and Ausloos (2005 and 2006), Ovcharuk and Piskun (2009), Guhathakurta et al. (2010), Bastos and Caiado (2011) and Goswami et al. (2012) apply it to stock markets; Crowley (2008), and Crowley and Schultz (2011) apply it to economic growth; Barkoulas (2008) apply it to monetary aggregates,..... Other applications in the field of Economics are included in Salzano and Kirman (2005).

The starting point of the RQA is the following function:

$\mathrm{d}_{\mathrm{ij}}= \begin{cases}1, & \text { if }\|\mathrm{x}(\mathrm{i})-\mathrm{x}(\mathrm{j})\|<\mathrm{r} \\ 0, & \text { if }\|\mathrm{x}(\mathrm{i})-\mathrm{x}(\mathrm{j})\| \geq \mathrm{r} .\end{cases}$

The indicator function (1) collects the information given by the RP in a binary symmetric $n \times n$ matrix (which we will call "recurrence matrix", RM), with $n$ being the number of data points. Among the various patterns that can be recognized in the RM, the RQA focuses its attention on the points forming lines parallel to the main $45^{\circ}$ diagonal. The presence of such diagonal structuring is related to the existence of both spatial and time correlation, a characteristic of the existence of general dependence in the data. Considering that this matrix is symmetric, the RQA uses in practice the upper (or lower) triangular part, excluding the main diagonal: from now on, TRM. In Aparicio et al. (2008), the distribution of the points of the TRM that form lines parallel to the main diagonal is contained in three indicators: \%DET (Percentage of points in diagonal lines), $\bar{L}$ (Average number of points per line) and $A L L$ (Average length of the lines). Each of these three indicators leads to a test procedure. The starting point is the random variable, $L$, which assigns to each element of the TRM the size of the line to which this element belongs. Moreover, it is proven that the probability distribution of $L$ can be expressed as:

$$
\begin{gathered}
\mathrm{P}(L)=L \cdot\left\{\left[\prod_{i=0}^{L-1} \frac{N R E C-i}{N P-i}\right]+\left[\prod_{i=0}^{L-1} \frac{N R E C-i}{N P-i} \cdot \frac{N P-N R E C}{N P-L} \cdot 2 \cdot(n-L-1)\right]+\right. \\
\left.+\left[\prod_{i=0}^{L-1} \frac{N R E C-i}{N P-i} \cdot \prod_{i=0}^{1} \frac{N P-N R E C-i}{N P-L-i}\right] \cdot \frac{(n-L-1) \cdot(n-L-2)}{2}\right\} \cdot \frac{1}{N R E C},
\end{gathered}
$$

where: $\mathrm{P}(L)=$ the probability that a recurrent point of the TRM belongs to a line of length $L(L=1$, ...., $n-1)$.

$N R E C=$ the number of recurrent points or number of ones of the TRM.

$N P=$ the total elements of the TRM.

If the data series were completely random, all the points of the TRM would have the same probability of being recurrent points. These points would form lines of different sizes according to the probability

\footnotetext{
${ }^{2}$ Instead of the original series, it is also possible to elaborate the RP using an m-dimensional embedding of the series (after applying the so-called "Time Delay Method").
} 
distribution given in (2). Considering that $N P=\frac{n \cdot(n-1)}{2}$, this probability distribution only depends on the number of recurrent points $(N R E C)$ and the number of data points $(n)$.

In these conditions, the expected value of $L$ will be $\mathrm{E}[L]=\sum_{L=1}^{n-1} L \cdot P(L)$, and its variance, $\operatorname{Var}[L]=$ $\sum_{L=1}^{n-1}[L-E(L)]^{2} \cdot P(L)$

This probability distribution is the key tool that enables us to test whether, in a TRM obtained from a real series, the distribution of points forming line segments differs significantly from that which would be expected if the series under examination were absolutely random. In the three proposed methods, the null hypothesis will be that the series has been generated from a purely random process. Therefore, the rejection of this hypothesis would be evidence that the series presents general dependence (and, hence, some kind of structure). The three test procedures are the following:

1.-Test based on $\bar{L}: \bar{L}$ is the average number of points per line. It can be demonstrated that $\bar{L}$ $=\sum_{L=1}^{n-1} L \cdot f(L)$, where $f(L)$ is the proportion of recurrence points in lines of length $L$, and:

$$
\bar{L} \stackrel{D}{\longrightarrow} \mathrm{N}\left(\mathrm{E}[L], \frac{\operatorname{Var}[L]}{N R E C}\right),
$$

If the value of this indicator is significantly greater than $\mathrm{E}[L]$, we can conclude that the number of recurrent points on lines parallel to the diagonal would be sufficiently high to reject the serial independence of the data.

2.-Test based on the \%DET: \%DET is the "percentage of determinism" and is defined as: \%DET = $100 \times \frac{N P D}{N R E C}$, where $N P D$ is the number of points on lines parallel to the main diagonal, considering that a line is formed with a minimum of at least two adjacent points. In this case, we will use the statistic:

$$
\chi^{2}=\frac{(N P D-N R E C \cdot \mathrm{E}[\% D E T])^{2}}{N R E C \cdot \mathrm{E}[\% D E T]}+\frac{\{(N R E C-N P D)-N R E C \cdot(1-\mathrm{E}[\% D E T])\}^{2}}{N R E C \cdot(1-\mathrm{E}[\% D E T])} \text { (3) where }
$$

$\mathrm{E}[\% D E T]$ is the expected value of \%DET under the null hypothesis.

It can be proved that, under certain conditions, (3) follows a $\chi^{2}$ distribution with one degree of freedom. Since it is a one-tailed test, we will only reject the null hypothesis if the value of $\% D E T$ is significantly higher than that corresponding to a purely random process, E[\%DET]. On the contrary, if $\% D E T$ is lower than E[\%DET], even if the value of the statistic were high (superior to the pre-established critical point), it would make no sense to reject the null hypothesis.

3.-Test based on the $A L L: A L L$ is the average line length, defined as the ratio between the total number of recurrent points and the total number of lines. It can be demonstrated that $A L L=$

$$
\frac{1}{\sum_{L=1}^{n-1} \frac{f(L)}{L}},
$$

and so $A L L^{-1}=\sum_{L=1}^{n-1} \frac{f(L)}{L}$.

The latter statistic has the following asymptotic distribution:

$$
A L L^{-1} \stackrel{D}{\longrightarrow} N\left(\mathrm{E}\left[L^{-1}\right], \frac{\operatorname{Var}\left[L^{-1}\right]}{N R E C}\right)
$$

In this case, if $A L L^{-1}$ is significantly lower than $\mathrm{E}\left[A L L^{-1}\right]$, the null hypothesis of purely random data would be rejected.

\section{General dependence in exchange rate series}

In this section, we apply the above methodology to the exchange rate series of four currencies against the US Dollar: Japanese Yen, British Pound, Swiss Franc, and Australian Dollar. We use the closing daily spot exchange rates from January 2, 1975 to December 31, 2012 (9,607 observations). Our analysis is carried out with the daily returns of the series, rather than the originals, in order to avoid any problems related to 
nonstationarity. For each exchange rate, as well as applying the test procedures to the series of returns, we apply them to the reshuffled data and to the standardized $\operatorname{GARCH}(1,1)$ residuals of the series. The possible existence of structure should disappear if the data are reshuffled. The objective of the GARCH model is to capture the serial correlation of volatility. This is a kind of non-linear structure, of a stochastic nature, which appears very often in financial series. Hence, we believe that if the original series is filtered with a GARCH model, and the structure still appears in the residuals of the model, this would be evidence of another kind of non-linear behavior, perhaps of a deterministic nature. The results are displayed in Table 1.

This table shows, for each of the series, the estimated value of the indicators $\bar{L}, A L L$ and \%DET, and the probability value associated with the three tests. The bottom row shows the values of $\mathrm{E}(\bar{L}), \mathrm{E}(A L L)$ and $\mathrm{E}(\% D E T)$, that is, the expected value of the statistics if the data series were purely random. The cells of the \%DET statistic in which there are no $p$-values are cases in which the \%DET is lower than E[\%DET]. In these cases, as we established previously, the null hypothesis is accepted directly.

Table 1: Results of the tests for the original and reshuffled series, and for the GARCH residuals of the series

\begin{tabular}{lllllll}
\hline & $\overline{\boldsymbol{L}}$ & ALL & \%DET & $\begin{array}{l}\overline{\boldsymbol{L}} \text { p-value } \\
\end{array}$ & $\begin{array}{l}\text { ALL } \\
\text { p-value }\end{array}$ & $\begin{array}{l}\text { \%DET } \\
\text { p-value }\end{array}$ \\
\hline Japanese Yen / \$ & 1.2577 & 1.1228 & 20.40 & 0.0000 & 0.0000 & 0.0000 \\
Jap. Yen / \$ reshuffled & 1.2212 & 1.1104 & 18.88 & 1.0000 & 1.0000 & - \\
GARCH residuals & 1.2277 & 1.1131 & 19.24 & 0.0000 & 0.0000 & 0.0000 \\
& & & & & & \\
British Pound / \$ & 1.2802 & 1.1246 & 20.61 & 0.0000 & 0.0000 & 0.0000 \\
$\begin{array}{l}\text { B. Pound / \$ reshuffled } \\
\text { GARCH residuals }\end{array}$ & 1.2221 & 1.1112 & 19.03 & 0.4889 & 0.1157 & 0.0739 \\
& 1.2307 & 1.1140 & 19.36 & 0.0000 & 0.0000 & 0.0000 \\
Swiss Franc / \$ & & & & & & \\
Swi. Franc / reshuffled & 1.2344 & 1.1163 & 19.69 & 0.0000 & 0.0000 & 0.0000 \\
GARCH residuals & 1.2215 & 1.1107 & 18.93 & 0.9915 & 0.9984 & - \\
& 1.2206 & 1.1103 & 18.89 & 1.0000 & 1.0000 & - \\
Australian Dollar / \$ & 1.3168 & 1.1470 & 23.43 & 0.0000 & 0.0000 & 0.0000 \\
Aus. Dollar / \$ reshuffled & 1.2204 & 1.1103 & 18.88 & 1.0000 & 1.0000 & - \\
GARCH residuals & 1.2623 & 1.1267 & 20.98 & 0.0000 & 0.0000 & 0.0000 \\
& & & & & & \\
\hline \multicolumn{1}{c}{ E(statistic): } & 1.2222 & 1.1111 & 19.00 & & & \\
\hline
\end{tabular}

The results obtained allow us to conclude that, for the usual significance levels:

-All four series show strong evidence of some kind of structure.

-As expected, this structure is lost when the series are reshuffled.

-Two different behaviors are observed after the GARCH filtering: three of the series maintain the structure (Japanese Yen, British Pound and Australian Dollar) and the other (Swiss Franc) does not. Thus, while for the latter, the underlying structure is explained by a GARCH process, the first group could present another type of structure, perhaps non-linear deterministic.

-The three tests ( $\bar{L}, A L L$ and \%DET) offer the same conclusions in all cases.

These results reflect the average behavior of the series over a period of more than thirty years. It is highly probable that this behavior has not been homogenous throughout the period. For this reason, to better understand the underlying dynamics, we also apply our analysis to consecutive sub-periods of the series. Specifically, we have considered three sub-periods: the first, from January 2, 1975 to December 31, 1982; the second from January 4, 1983 to December 31, 1998, and the third from January 4, 1999 to December 31, 2012. The results obtained are displayed in Table 2.

From Table 2, the following conclusions can be drawn:

-For the four original series of exchange rates, the null hypothesis would be rejected in the three subperiods. This indicates that in the three sub-periods there is evidence of some type of structure.

-This is not the case for the GARCH residuals of the series. In the first sub-period, for three of the four 
series (Japanese Yen, British Pound and Australian Dollar) the null hypothesis would be rejected, while it cannot be rejected for the Swiss Franc. In the second sub-period, two series (the British Pound and the Australian Dollar) allow the rejection of the null hypothesis, while the other two (the Japanese Yen and the Swiss Franc) do not. Finally, in the third sub-period, the null hypothesis could not be rejected for any of the series at any level of significance. To summarize, in the first sub-period, only the Swiss Franc presents a structure that can be explained by a GARCH process. In the second sub-period, the Japanese Yen and the Swiss Franc behave in this way. In the third sub-period, this occurs for all series.

-In general terms, from the values of the statistics and the probability values, we observe that the greatest degree of structure appears in the first sub-period. This decreases in the second sub-period and decreases again in the third. This is true for the original series as well as for the GARCH residuals.

Table 2: Results of the tests for the three sub-periods of the series

\begin{tabular}{|c|c|c|c|c|c|c|c|}
\hline & & $\overline{\boldsymbol{L}}$ & $A L L$ & $\% D E T$ & $\begin{array}{l}\bar{L} \\
p \text {-value }\end{array}$ & $\begin{array}{l}A L L \\
p \text {-value }\end{array}$ & $\begin{array}{l}\% D E T \\
p \text {-value }\end{array}$ \\
\hline \multicolumn{8}{|l|}{ Japanese Yen / \$ } \\
\hline \multirow[t]{3}{*}{ Original series } & Period 1: & 1.4240 & 1.1774 & 26.43 & 0.0000 & 0.0000 & 0.0000 \\
\hline & Period 2: & 1.2406 & 1.1189 & 20.02 & 0.0000 & 0.0000 & 0.0000 \\
\hline & Period 3: & 1.2281 & 1.1135 & 19.31 & 0.0000 & 0.0000 & 0.0000 \\
\hline \multirow[t]{3}{*}{ GARCH residuals } & Period 1: & 1.2518 & 1.1236 & 20.65 & 0.0000 & 0.0000 & 0.0000 \\
\hline & Period 2: & 1.2237 & 1.1116 & 19.05 & 0.0032 & 0.0426 & 0.1864 \\
\hline & Period 3: & 1.2184 & 1.1091 & 18.70 & 1 & 1 & - \\
\hline \multicolumn{8}{|l|}{ British Pound / \$ } \\
\hline \multirow[t]{3}{*}{ Original series } & Period 1: & 1.4957 & 1.1789 & 26.37 & 0.0000 & 0.0000 & 0.0000 \\
\hline & Period 2: & 1.2412 & 1.1193 & 20.09 & 0.0000 & 0.0000 & 0.0000 \\
\hline & Period 3: & 1.2309 & 1.1150 & 19.53 & 0.0000 & 0.0000 & 0.0000 \\
\hline \multirow[t]{3}{*}{ GARCH residuals } & Period 1: & 1.2744 & 1.1311 & 21.54 & 0.0000 & 0.0000 & 0.0000 \\
\hline & Period 2: & 1.2265 & 1.1133 & 19.33 & 0.0000 & 0.0000 & 0.0000 \\
\hline & Period 3: & 1.2181 & 1.1092 & 18.73 & 1 & 1 & - \\
\hline \multicolumn{8}{|l|}{ Swiss Franc / \$ } \\
\hline \multirow[t]{3}{*}{ Original series } & Period 1: & 1.2781 & 1.1347 & 22.08 & 0.0000 & 0.0000 & 0.0000 \\
\hline & Period 2: & 1.2289 & 1.1142 & 19.43 & 0.0000 & 0.0000 & 0.0000 \\
\hline & Period 3: & 1.2245 & 1.1119 & 19.15 & 0.0001 & 0.0027 & 0.0302 \\
\hline \multirow[t]{3}{*}{ GARCH residuals } & Period 1: & 1.2211 & 1.1104 & 18.90 & 0.7984 & 0.8374 & - \\
\hline & Period 2: & 1.2209 & 1.1105 & 18.89 & 0.9831 & 0.9646 & - \\
\hline & Period 3: & 1.2162 & 1.1082 & 18.57 & 1 & 1 & - \\
\hline \multicolumn{8}{|l|}{ Austr. Dollar / \$ } \\
\hline \multirow[t]{3}{*}{ Original series } & Period 1: & 1.2552 & 1.1251 & 20.86 & 0.0000 & 0.0000 & 0.0000 \\
\hline & Period 2: & 1.2528 & 1.1248 & 20.85 & 0.0000 & 0.0000 & 0.0000 \\
\hline & Period 3: & 1.2360 & 1.1173 & 19.85 & 0.0000 & 0.0000 & 0.0000 \\
\hline \multirow[t]{3}{*}{ GARCH residuals } & Period 1: & 1.2530 & 1.1239 & 20.71 & 0.0000 & 0.0000 & 0.0000 \\
\hline & Period 2: & 1.2289 & 1.1140 & 19.39 & 0.0000 & 0.0000 & 0.0000 \\
\hline & Period 3: & 1.2178 & 1.1089 & 18.69 & 1 & 1 & - \\
\hline
\end{tabular}

We could ask why the four currencies behave distinctly in the different sub-periods. A detailed analysis of the behavior of the four series throughout all the sub-periods exceeds our stated objective, though it does present a line of future research. Our conjecture is that two fundamental factors exist that influence the degree of structure of the series of exchange rates:

-The greater development of financial markets in general, and of foreign currency markets in particular (a greater number of participating agents, a greater number and volume of operations, more information for 
agents, fewer restrictions on mobility of capital between countries) acts in favor of the serial independence of exchange rates. That is, it causes the degree of structure to be lessened. In other words, our conjecture is that, if few agents exist (and/or some who have significant influence) and few operations occur, it is more probable that patterns of structure can be detected than if many agents interact with different motivations and behaviors.

-The greater the intervention of the authorities (directly or indirectly) in foreign exchange markets, the greater would be the degree of structure of the series - both for the shocks generated by these interventions, and for their influence on certain behaviour patterns which emerge from them. Both arguments could help to explain:

i) Why structure exists in the first sub-period in all cases: a very recent system of flexible exchange rates, strong intervention by the authorities, poorly developed foreign exchange markets.

ii)The lack of certain structures in the second and third sub-period: the growing development of foreign exchange markets, regular interventions by the authorities, greater degree of independence of the central banks.

iii)When we consider the whole period, this would also help to explain the different behavior of the Swiss franc in comparison to the rest. During this period:

- The British pound was in a regime of semi-fixed exchange rates, during which the currency was confined within pre-established fluctuation bands.

- The Japanese economy suffered a real estate and financial crisis that forced the Japanese monetary authorities to strongly intervene in the foreign exchange markets.

- The Australian dollar entered the floating rate regime late, in 1983.

Finally, to support these arguments, we divide the third sub-period into two smaller ones that are clearly differentiated regarding the degree of intervention by the authorities. We select 2007 as a cutoff point between both sub-periods, so that the first sub-period corresponds to a time of economic expansion with few interventions, while the second covers the current economic crisis, during which the authorities have taken quite a number of extraordinary measures that have clearly influenced the currency markets.

We apply the test procedure to the previous series of exchange rates, together with the Euro/Dollar series. ${ }^{3}$ The obtained results are presented in Table 3.

These results confirm our previous argument: in the first sub-period none of the series showed evidence of structure, while in the second, some type of structure was detected in all series (in particular the GARCH structure).

\section{Conclusion}

In this paper we have applied three tests, based on Recurrence Quantification Analysis, to the exchange rate returns of four currencies against the US dollar, with two objectives: to discover whether a nonlinear structure underlies the series, and, if such a structure exists, to find evidence of its possible deterministic nature. The results obtained confirm the existence of non-linear structure in all cases: in one case (the Swiss Franc) the non-linearity seems to be completely explained by a GARCH process. However, in the other three (the British Pound, the Australian Dollar and the Japanese Yen), the nonlinear structure is maintained for the standardized GARCH residuals of the series. This could suggest that the underlying structure has a deterministic nature.

To analyze whether, during the period under study, there are any significant changes in the underlying dynamics, we have divided the series into three consecutive sub-periods, and applied the same methodology to each. Our main conclusion, after applying the GARCH filter, is that there are significant variations in the behavior (presence or absence of structure) of the series in the different sub-periods. Significantly, in general, the possible non-linear deterministic structure disappears from all the series over time. The results obtained seem to support the hypothesis that the greater development of currency markets and the diminishing intervention of the authorities favor the non-existence of structure in the exchange rate series. The latter is clearly shown when the third sub-period is divided into two parts, with the second part including the current economic and financial crisis. Finally, we want to emphasize that our intention is to provide evidence that contributes to an on-going discussion: the modeling of exchange rates. New theoretical explanations are necessary to help understand the complex behavior of these series, and their seeming disconnect from other relevant economic variables.

\footnotetext{
${ }^{3}$ We recall that the Euro was created January 1, 1999.
} 
Table 3: Results of the tests for the two divisions of the third sub-period

\begin{tabular}{|c|c|c|c|c|c|c|c|}
\hline & & $\overline{\boldsymbol{L}}$ & $A L L$ & $\% D E T$ & $\begin{array}{l}\bar{L} \\
p \text {-value }\end{array}$ & $\begin{array}{l}\text { ALL } \\
p \text {-value }\end{array}$ & $\begin{array}{l}\text { \%DET } \\
\text { p-value }\end{array}$ \\
\hline \multicolumn{8}{|l|}{ Japanese Yen / \$ } \\
\hline \multirow[t]{2}{*}{ Original series } & Period 3-1 & 1.2179 & 1.1083 & 18.54 & 0.9999 & 1 & - \\
\hline & Period 3-2 & 1.2409 & 1.1203 & 20.30 & 0 & 0 & 0 \\
\hline \multirow[t]{2}{*}{ GARCH residuals } & Period 3-1 & 1.2131 & 1.1059 & 18.19 & 1 & 1 & - \\
\hline & Period 3-2 & 1.2222 & 1.1112 & 19.02 & 0.4421 & 0.3833 & 0.7443 \\
\hline \multicolumn{8}{|l|}{ British Pound / \$ } \\
\hline \multirow[t]{2}{*}{ Original series } & Period 3-1 & 1.2190 & 1.1096 & 18.80 & 0.9959 & 0.9886 & - \\
\hline & Period 3-2 & 1.2401 & 1.1190 & 20.09 & 0 & 0 & 0 \\
\hline \multirow[t]{2}{*}{ GARCH residuals } & Period 3-1 & 1.2164 & 1.1082 & 18.58 & 1 & 1 & - \\
\hline & Period 3-2 & 1.2189 & 1.1096 & 18.79 & 0.9806 & 0.9685 & - \\
\hline \multicolumn{8}{|l|}{ Swiss Franc / \$ } \\
\hline \multirow[t]{2}{*}{ Original series } & Period 3-1 & 1.2191 & 1.1099 & 18.86 & 0.9960 & 0.9715 & - \\
\hline & Period 3-2 & 1.2353 & 1.1167 & 19.73 & 0 & 0 & 0 \\
\hline \multirow[t]{2}{*}{ GARCH residuals } & Period 3-1 & 1.2176 & 1.1092 & 18.75 & 1 & 0.9992 & - \\
\hline & Period 3-2 & 1.2241 & 1.1114 & 19.00 & 0.0635 & 0.2566 & 0.7862 \\
\hline \multicolumn{8}{|l|}{ Austr. Dollar / \$ } \\
\hline \multirow[t]{2}{*}{ Original series } & Period 3-1 & 1.2233 & 1.1105 & 19.05 & 0.1079 & 0.1699 & 0.3970 \\
\hline & Period 3-2 & 1.2510 & 1.1240 & 20.73 & 0 & 0 & 0 \\
\hline \multirow[t]{2}{*}{ GARCH residuals } & Period 3-1 & 1.2169 & 1.1084 & 18.62 & 1 & 1 & - \\
\hline & Period 3-2 & 1.2190 & 1.1101 & 18.90 & 0.9754 & 0.8613 & 0.4998 \\
\hline \multicolumn{8}{|l|}{ Euro / \$ } \\
\hline \multirow[t]{2}{*}{ Original series } & Period 3-1 & 1.2168 & 1.1084 & 18.62 & 1 & 1 & - \\
\hline & Period 3-2 & 1.2291 & 1.1141 & 19.42 & 0 & 0 & 0 \\
\hline \multirow[t]{2}{*}{ GARCH residuals } & Period 3-1 & 1.2127 & 1.1065 & 18.34 & 1 & 1 & - \\
\hline & Period 3-2 & 1.2193 & 1.1100 & 18.87 & 0.9617 & 0.8893 & - \\
\hline
\end{tabular}

Acknowledgments: This work was supported by the Spanish Ministry of Science and Innovation [EC02009-07936, EC02010-14929]; and by the Government of Aragon [Consolidate Group S10, Consolidate Group S21].

\section{References}

Aparicio, T., Pozo, E. \& Saura, D. (2008). Detecting determinism using recurrence quantification analysis: Three test procedures. Journal of Economic Behavior and Organization, 65(3-4), 768-787.

Aparicio, T., Pozo, E. \& Saura, D. (2011). Detecting determinism using recurrence quantification analysis: a solution to the problem of embedding. Studies of Nonlinear Dynamics and Econometrics, 15(1), 110.

Barkoulas, J. T. (2008). Testing for deterministic monetary chaos: Metric and topological diagnostics. Chaos, Solitons \& Fractals, 38(4), 1013-1024.

Bask, M. (2007). Chartism and exchange rate volatility. International Journal of Finance and Economics, 12(3), 301-316.

Bastos, J. A. \& Caiado, J. (2011). Recurrence quantification analysis of global stock markets. Physica A, 390(7), 1315-1325.

Belaire, J., Contreras D. \& Tordera L. (2002). Assessing nonlinear structures in real exchange rates using 
recurrence plot strategies. Physica D, 171(4), 249-264.

Brooks, C. \& Hinich, M. (1998). Episodic nonstationarity in exchange rates. Applied Economics Letters, 5(8), 719-722.

Casdagli, M. C. (1997). Recurrence plots revisited. Physica D, 108(1-2), 12-44.

Crowley, P. M. (2008). Analyzing convergence and synchronicity of business and growth cycles in the euro area using cross recurrence plots. European Physical Journal Special Topics, 164(1), 67-84.

Crowley, P. M. \& Schultz A. (2011). Measuring the Intermittent Synchronicity of Macroeconomic Growth in Europe. International Journal of Bifurcation and Chaos, 21(4), 1215-1231.

Das, A. \& Das, P. (2007). Chaotic Analysis of the Foreign Exchange Rates. Applied Mathematics and Computation, 185(1), 388-396.

De Grauve, P. \& Grimaldi, M. (2005). The exchange rate and its fundamental in a complex world. Review of International Economics, 13(3), 549-575.

De Grauve, P. \& Grimaldi, M. (2006). Exchange rate puzzles: A tale of switching attractors. European Economic Review, 50(1), 1-33.

Eckmann, J. P., Kamphorst, S. \& Ruelle, D. (1987). Recurrence plots of dynamical systems. Europhysics Letters, 4(9), 973-977.

Evans, M. D. \& Lyons, R. K. (2002). Order flow and exchange rate dynamics. Journal of Political Economy, $110(1), 170-180$.

Fabretti, A. \& Ausloos, M. (2005). Recurrence plot and recurrence quantification analysis techniques for detecting a critical regime. Examples from financial market indices. International Journal of Modern Physics C, 16(5), 671-706.

Fabretti, A. \& Ausloos, M. (2006). Recurrence analysis near the NASDAQ crash of April 2000. In: H. Takayasu (Ed.), Practical Fruits of Econophysics (pp. 52-56). Tokyo: Springer.

Franses, P. H. \& Van Homelen, P. (1998). On forecasting exchange rates using neural networks. Applied Financial Economics, 8(6), 589-596.

Goswami, B. Ambika, G., Marwan, N. \& Kurths, J. (2012). On interrelations of recurrences and connectivity trends between stock indices. Physica A, 391(18), 4364-4376.

Guhathakurta, K., Bhattacharya, A. \& Chowdhury, R. (2010). Using recurrence plot analysis to distinguish between endogenous and exogenous stock market crashes. Physica A, 389(9), 1874-1882.

Hinich, M. J. \& Serletis, A. (2007). Episodic Nonlinear Event Detection in the Canadian Exchange Rate. Journal of the American Statistical Association, 102(477), 68-74.

Hirata, Y. \& Aihara, K. (2012). Timing matters in foreign exchange markets. Physica A, 391(3), 760-766.

Holyst, J. A., Zebrowska, M. \& Urbanowicz, K. (2001). Observations of deterministic chaos in financial time series by recurrence plots, can one control chaotic economy?. The European Physical Journal B, 20(4), 531-535.

Hsie, D. A. (1989). Modeling heteroscedasticity in daily foreign exchange rates. Journal of Business and Economic Statistics, 7(3), 307-317.

Lisi, F. \& Schiavo, R. A. (1999). A comparison between neural networks and chaotic models for exchange rate prediction. Computational Statistics and Data Analysis, 30(1), 87-102.

Mitra, S. \& Mitra, A. (2006). Modeling exchange rates using wavelet decomposed genetic neural networks. Statistical Methodology, 3(2), 103-124.

Mizrach, B. (1996). Determining delay time for the phase space reconstruction with application to the FF/DM exchange rate. Journal of Economic Behavior \& Organization, 30(3), 369-381.

Nag, A. K. \& Mitra, A. (2002). Forecasting daily foreign exchange rates using genetically engineered neural networks. Journal of Forecasting, 21(7), 501-511.

Neely, C. (1999). Target zones and conditional volatility: The role of realignments. Journal of Empirical Finance, 6(2), 177-192.

Obstfeld, M. \& Rogoff, K. (1995). Exchange rate dynamics redux. Journal of Political Economy, 103(3), 624660.

Obstfeld, M. \& Rogoff, K. (2000). The six major puzzles in international macroeconomics. Is there a common cause? NBER Macroeconomics Annual, 15, 339-390.

Ovcharuk, M. P. \& Piskun, A. V. (2009). Recurrence quantification analysis of stockmarket crashes. Ekonomika i region, 1(20), 179-184.

Salzano, M. \& Kirman, A. (2005). Economics: Complex Windows, Milan: Springer-Verlag.

Serletis, A. \& Shahmoradi, A. (2004). Absence of chaos and 1/f spectra, but evidence of TAR nonlinearities, in the Canadian exchange rate. Macroeconomics Dynamics, 8(4), 543-551.

Strozzi, F., Zaldívar, J. M. \& Zbilut, J. P. (2002). Application of nonlinear time series analysis techniques to high-frequency currency exchange data. Physica A, 312(3-4), 520-538.

Strozzi, F., Zaldívar, J. M. \& Zbilut, J. P. (2007). Recurrence quantification analysis and state space 
divergence reconstruction for financial time series analysis. Physica A, 376, 487-499.

Webber Jr., C. L. \& Zbilut, J. P. (1994). Dynamical assessment of physiological systems and states using recurrence plot strategies. Journal of Applied Physiology, 76(2), 965-973.

West, K. D. \& Cho, D. (1995). The predictive ability of several models of exchange rate volatility. Journal of Econometrics, 69(2), 367-391.

Zbilut, J. P. \& Webber Jr., C. L. (1992). Embeddings and delays as derived from quantification of recurrence plots. Physics Letters A, 171(3-4), 199-203. 